\title{
Research on nanosatellite thermal cycling test applicability
}

\author{
Xiyuan $\mathrm{Li}^{1,2, a}$, Xiaoning Yang ${ }^{2}$, Yonghong Shang ${ }^{2}$, Yanqiang $\mathrm{Bi}^{2}$, Jing Wang ${ }^{2}$ and Guiping Lin ${ }^{1}$ \\ ${ }^{1}$ Beihang University, Beijing, China \\ ${ }^{2}$ Beijing Institute of Spacecraft Environment Engineering, Beijing, China
}

\begin{abstract}
In order to verify the spacecraft performance in extreme temperature and vacuum, and to screen spacecraft early defect, generally spacecraft TV (Thermal Vacuum) test should be carried out before launch. Designed in small size and with low cost, nanosatellite is made from a large number of COTS (Commercial off the shelf) components; therefore, the test should be low-cost, simple and quick. With the intention of screen out early defects of the product in lower cost, nanosatellite developers usually use TC (Thermal Cycling) test to partially replace the TV test because TV test is more expensive. However, due to the air convection, TC test is different from TV test in heat transfer characteristics, which may be over-test or short-test in TC test. This paper aims to explore the applicability of different nanosatellites in TC/TV test. Using rule number analysis method, Heat Transfer model in vacuum and ambient environment has been built to analyse the characteristics of heat transfer under different temperature and characteristic length, and to deliver the recommended limits on using TC test instead of the TV test. The CFD and test methods are applied to verify the rule number analysis above.
\end{abstract}

\section{Introduction}

Limited by cost, time and other constraints, nanosatellites developers generally avoid long time TV (Thermal Vacuum) test in TV chamber. Some developers shorten the test by reducing the number of cycles or soak time; while others try to simplify the TV test by vacuum test, TC (Thermal Cycling) test and high and low temperature start-up test[1]. Firstly, a vacuum test, including system electrical performance test, is carried out in a small vacuum chamber (no 1: 2 limit) to verify the ability of the system working in vacuum and at high temperatures. Secondly, a TC test (including TC tolerance and TC performance) is applied to screen early defects of the system and to verify the system performance at

\footnotetext{
a Corresponding author: 1xy_422@msn.com
} 
low temperatures. Finally, a hot and cold start-up test is employed to verify the start ability of the system at high and low temperature [2]. To sum up, a large, complex, high-cost test could be cut into multiple small, simple, low-cost test in nanosatellite verification; as showed in Table 1, different tests meet different purposes of TV test.

Table 1. Test replacement

\begin{tabular}{|l|l|}
\hline TV Test Purpose & Nanosatellite test \\
\hline Screening early defects & TC test \\
\hline Verify the ability to work at high temperatures coupled with the vacuum environment & vacuum test \\
\hline Verify the ability to work at low temperatures coupled with the vacuum environment & TC test \\
\hline $\begin{array}{l}\text { Verify the ability to withstand extremely high and low temperature in non-operating } \\
\text { state }\end{array}$ & TC tolerance test \\
\hline Verify system startup capability at high and low temperature & hot/cold start-up test \\
\hline
\end{tabular}

As showed in the table above, some purposes can be achieved by a simple test: the TC test and TV test can achieve the same purpose in screening early defect; vacuum test can also perfectly achieve the purpose of verifying the ability of system working in the environment coupled with extremely high temperature and vacuum (via heating device in satellite); Hot/Cold start-up test can verify the system start in high and low temperature; and TC tolerance test can verify the ability of system survive extremely high and low temperature in non-operating state.

However, regarding "verifying system the ability to work at low temperatures coupled with the vacuum environment", there are certain differences between the TC and TV test. Initially, the TC test has no vacuum environment, which is a test condition and can only be tailored. Secondly, because of natural convection, heat transfer characteristics in the satellite should have some differences between TC and TV test. This paper describes the internal temperature distribution differences between TV test and TC test of nanosatellite via rule number analysis method, and validate the model by CFD simulation and test.

\section{Rule number analysis}

In international standards draft "Space Systems - Design Qualification And Acceptance Tests Of Small-Scale Satellite And Units Seeking Low-Cost And Fast-Delivery", the rule number analysis method was employed for nanosatellite TC applicability research, and a $50 \mathrm{~W} / \mathrm{m}^{2}$ heat flux threshold was set for TC test. It is mainly for a single external shell temperature $(300 \mathrm{~K})$ and completely radiation heat transfer state[3], which has certain differences with the actual test environment. This paper constructs concentric sphere model to simulate heat transfer in satellite: the inside sphere is heat source, which has heat power $\mathrm{Q}(\mathrm{w})$, radius $\mathrm{R} 1(\mathrm{~m})$ and temperature $\mathrm{T} 1(\mathrm{k})$; while the outer sphere is satellite shell, which has radius $\mathrm{R} 2(\mathrm{~m})$ and temperature T2 $(\mathrm{k})$. The model is showed in Figure 1: 


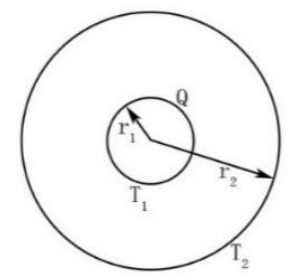

Figure 1. Heat transfer model

According to the basic formula of heat transfer, the heat flux through the inner shell in TV test can be expressed by the following equation,

$$
\frac{Q}{A_{1}}=\frac{\sigma\left(T_{1}^{4}-T_{2}^{4}\right)}{\frac{1}{\varepsilon_{1}}+\left(\frac{1}{\varepsilon_{2}}-1\right) \frac{A_{1}}{A_{2}}}
$$

Where $A_{1}$ is internal surface area $\left(\mathrm{m}^{2}\right), A_{2}$ is the external surface area $\left(\mathrm{m}^{2}\right), \varepsilon_{1}$ and $\varepsilon_{2}$ are the inner and outer surface emissivity. $\sigma$ is Stefan-Boltzmann constant. The heat flux through the inner shell in $\mathrm{TC}$ test can be expressed by the following equation,

$$
\frac{Q}{A_{1}}=\frac{\sigma\left(T_{1}^{4}-T_{2}^{4}\right)}{\frac{1}{\varepsilon_{1}}+\left(\frac{1}{\varepsilon_{2}}-1\right) \frac{A_{1}}{A_{2}}}+N u \frac{k_{a i r}}{r_{2}-r_{1}}\left(T_{1}-T_{2}\right)
$$

Where $k_{\text {air }}$ is air thermal conductivity $(\mathrm{W} / \mathrm{m} \cdot \mathrm{K}), N u$ is the Nusselt number, can be expressed by the following equation[4],

$$
\mathrm{Nu}=2+\frac{0.589(\mathrm{GrPr})^{1 / 4}}{\left(1+\left(0.4 \mathrm{C}_{9} / \mathrm{Pr}\right)^{9 / 15}\right)^{4 / 9}}=2+\frac{0.589(g P r)^{1 / 4}}{\left(1+\left(0.4 \zeta_{5} / P r\right)^{9 / 16}\right)^{4 / 9}} \times\left(\frac{a l^{3} \Delta t}{\nu}\right)^{1 / 4}
$$

Due to the small changes of the Prandtl number $P r$ with temperature, when consider it as 0.7 , the $N u$ can be simplified as follow,

$$
N u=2+\frac{0.589(g P r)^{1 / 4}}{\left(1+(0.4 C 9 / P r)^{9 / 16}\right)^{4 / 9}} \times\left(\frac{a l^{3} \Delta t}{\nu}\right)^{1 / 4} \approx 2+0.7344 \times\left(\frac{I^{3} \Delta t}{T^{\prime} \nu}\right)^{1 / 4}
$$

Where $l$ is characteristic length $(\mathrm{m}), \Delta t$ is temperature difference $\left({ }^{\circ} \mathrm{C}\right), T$ is qualitative temperature $(\mathrm{K}), \nu$ is kinematic viscosity $\left(\mathrm{m}^{2} / \mathrm{s}\right)$. When qualitative temperature and kinematic viscosity changed little, Nusselt number can be considered only relieve with temperature difference $\Delta t$ and characteristic length $l$, When assuming thermal conductivity changes little when temperature changed. Convection heat transfer can be considered only relieve with temperature difference $\Delta t$ and characteristic length $l$, heat flux in TV and TC can be expressed as follow,

$$
\begin{gathered}
\frac{Q}{A_{1}}=\frac{\sigma\left(T_{1}^{4}-T_{2}^{4}\right)}{\frac{1}{\varepsilon_{1}}+\left(\frac{1}{\varepsilon_{2}}-1\right) \frac{A_{1}}{A_{2}}} \\
\frac{Q}{A_{1}}=\frac{\sigma\left(T_{1}^{4}-T_{2}^{4}\right)}{\frac{1}{\varepsilon_{1}}+\left(\frac{1}{\varepsilon_{2}}-1\right) \frac{A_{1}}{A_{2}}}+\left(2+\left(\frac{0.7344}{T_{\nu}}\right)^{1 / 4} \times I^{3 / 4} \Delta t^{1 / 4}\right) \frac{k_{\text {air }}}{r_{2}-r_{1}}\left(T_{1}-T_{2}\right)
\end{gathered}
$$


Heat flux was selected for $\mathrm{x}$-axis, temperature difference between inner and outer shell was selected for y-axis. Outer shell temperature was set to $258 \mathrm{~K}$ according to the literature [2] low temperature test condition, and the inner shell radius was set to $0.05 \mathrm{~m}$. The temperature difference curve between TC and TV test with outer shell radius of $0.06,0.1,0.25 \mathrm{~m}$ in $258 \mathrm{~K}$ have been drew like Fig. 2-a, and curve in $300 \mathrm{~K}$ have been drew in Fig. 2-b.

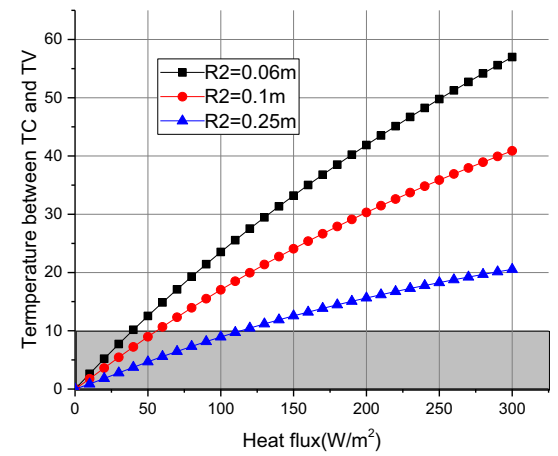

a Shell temperature $=258 \mathrm{~K}$

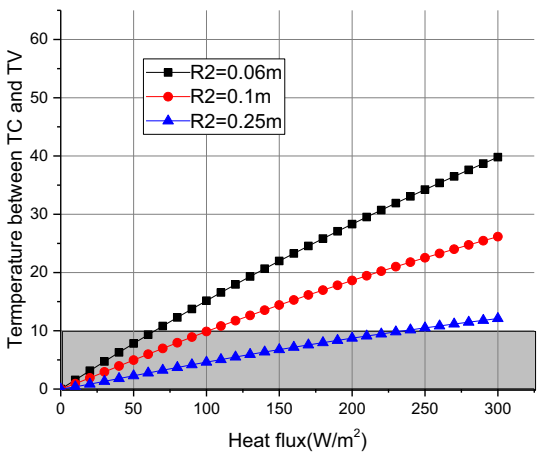

b shell temperature $=300 \mathrm{~K}$

Figure 2. The difference between TC and TV test in various characteristic length

As showed in Figure 2, temperature difference between inner and outer shell increase with heat flux of nanosatellite heat source, and heat exchange increase when outer shell reduced in diameter. The temperature curve also has some differences between $258 \mathrm{~K}$ and $300 \mathrm{~K}$. According to existing test standards [5,6], "If the worst-case temperature difference between the two environments is greater than $10^{\circ} \mathrm{C}$, TV testing shall be performed ". To ensure the maximize temperature difference below $10^{\circ} \mathrm{C}$, the heat flux should below $50 \mathrm{w} / \mathrm{m}^{2}$ when shell temperature is $300 \mathrm{~K}$, and below $40 \mathrm{~W} / \mathrm{m}^{2}$ when shell temperature is $258 \mathrm{~K}$. TC test mentioned in Table 1 should attain the purpose of verifying the ability of system performance at low temperatures. The estimated heat flux limits should be in accordance with the temperature difference under cold conditions. Therefore, the heat flux of the heat source in nanosatellite should below $40 \mathrm{~W} / \mathrm{m}^{2}$. Nanosatellite power density range is generally $0.3 \sim 2 \mathrm{~W} / \mathrm{kg}$ [7]. Consequently, not all the nanosatellites heat flux can meet the requirements of less than $40 \mathrm{~W} / \mathrm{m}^{2}$.

As to a general nanosatellite, its heat source power is about $1-5 \mathrm{~W}$, and its heat transfer is mainly in radiation. the TC alternative test threshold should be $40 \mathrm{~W} / \mathrm{m}^{2}$, or look up in Figure 2 using heat flux and characteristic length ratio.

When the internal heat source directly installed on a deck which was like a heat sink, it is assumed that one side of the device (20\% area) has thermal conductivity with deck, as showed in Figure 3 . The heat conduction will be more significant, which will not change between TC and TV test. Hence, the TC alternative test threshold should be much larger. 


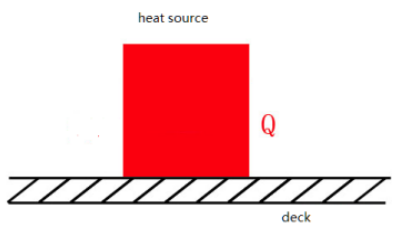

Figure 3. Heat source directly install on a deck

The contract was set to be dry contract. The deck was a honeycomb plate within $1 \mathrm{~cm}$ thickness, and its equivalent thermal conductivity can be expressed by the following equation,

$$
K=\frac{1}{\frac{1}{g}+\frac{1}{\lambda}}=\frac{1}{\frac{1}{50 \mathrm{~W} / \mathrm{m}^{2} \bullet K}+\frac{0.01 \mathrm{~m}}{1.5 \mathrm{~W} / \mathrm{m} \bullet \mathrm{K}}}=37.5 \mathrm{~W} / \mathrm{m}^{2} \bullet K
$$

where $g$ is contact heat transfer coefficient $\left(\mathrm{W} / \mathrm{m}^{2} \cdot{ }^{\circ} \mathrm{C}\right)$ and is set to $50 \mathrm{~W} / \mathrm{m}^{2} \cdot{ }^{\circ} \mathrm{C}$ for dry contract. Meanwhile, $\lambda$ is honeycomb equivalent thermal conductivity $\left(\mathrm{W} / \mathrm{m} \cdot{ }^{\circ} \mathrm{C}\right)$ and $l$ is honeycomb plate thickness.

Heat flux in TV and TC test can be expressed by the following equation,:

$$
\begin{gathered}
\frac{Q}{A_{1}}=\frac{\sigma T_{1}^{4}-T_{2}^{4}}{\frac{1}{\varepsilon_{1}}+\left(\frac{1}{\varepsilon_{2}}-1\right) \frac{A_{1}}{A_{2}}} \times 0.8+T_{1}-T_{2} \times k \times 0.2 \\
\frac{Q}{A_{1}}=\left[\frac{\sigma T_{1}^{4}-T_{2}^{4}}{\frac{1}{\varepsilon_{1}}+\left(\frac{1}{\varepsilon_{2}}-1\right) \frac{A_{1}}{A_{2}}}+\left(2+\left(\frac{0.7344}{T_{\nu^{\prime}}}\right)^{1 / 4} \times 1^{3 / 4} \Delta t^{1 / 4}\right) \frac{k_{a i r}}{r_{2}-r_{1}}\left(T_{1}-T_{2}\right)\right] \times 0.8+T_{1}-T_{2} \times k \times 0.2
\end{gathered}
$$

where $k$ is equivalent thermal coefficient (set to $37.5 \mathrm{~W} / \mathrm{m}^{2} \cdot{ }^{\circ} \mathrm{C}$ ). The curve of temperature difference between TV and TC test in different conditions is drew as Figure 4 。

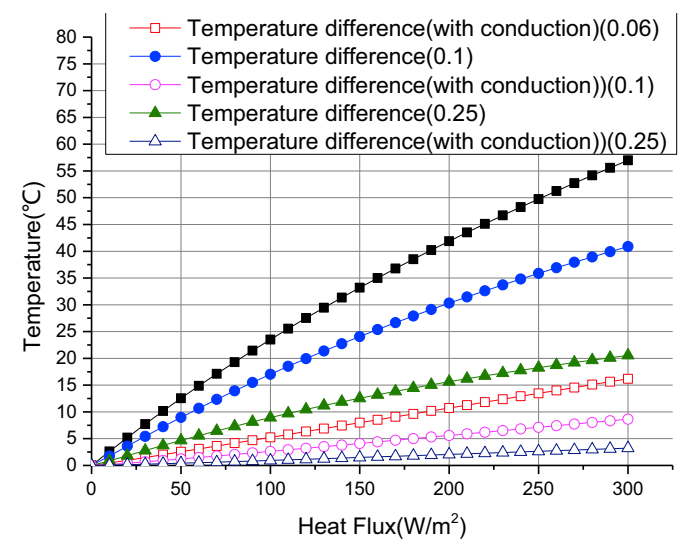

Figure 4. Temperature difference in TC and TV test

From the graph above, when the heat source set directly on the deck of nanosatellite, heat flux threshold can be enlarged to $100 \mathrm{~W} / \mathrm{m}^{2}$ to ensure the difference between TV and TC test under $10^{\circ} \mathrm{C}$. Concerning a higher characteristic length ratio or larger test article, heat flux threshold could be greater, which can be calculated by equ.9. 


\section{Validation}

\subsection{CFD simulation}

A Fluent model was used to verify the rule number analysis, including four units (two amplifiers and two TWT, traveling-wave tube) and six heat pipes in cabin body. The model was a rectangular cuboid which dimensions are $600(\mathrm{~L}) \times 400(\mathrm{~W}) \times 300(\mathrm{H}) \mathrm{mm}$, whose appearance and internal mesh showed below:
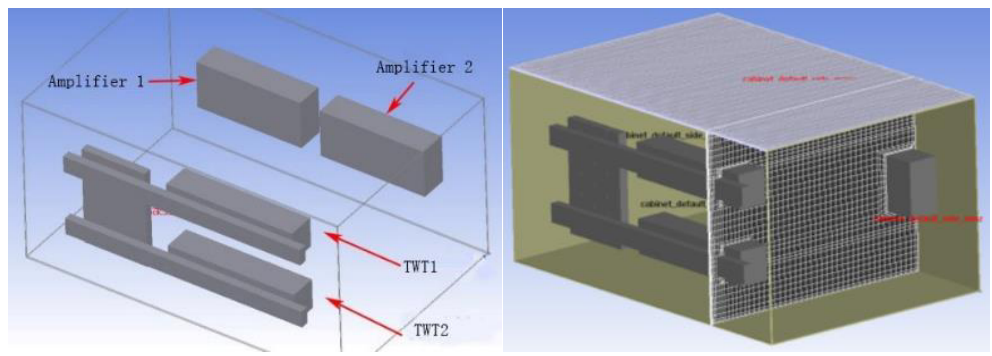

Figure 5. Simulation model and mesh

When the temperature of the outer shell is $-20^{\circ} \mathrm{C}$, the internal temperature distribution in $\mathrm{TV}$ and TC are given in Figure 6.

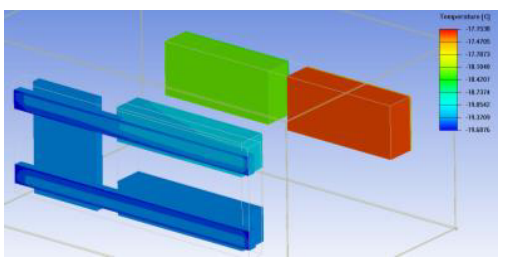

TC test

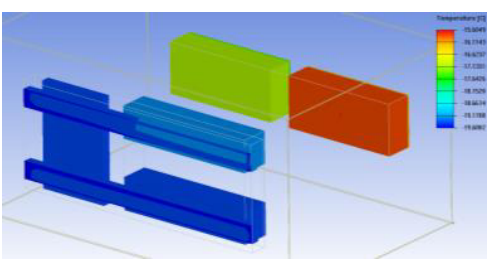

TV test

Figure 6. Temperature distribution

The outer shell temperature was set $253 \mathrm{~K}$. When the amplifiers power was $0.5 \mathrm{~W}, 1 \mathrm{~W}, 2 \mathrm{~W}, 5 \mathrm{~W}$ and $10 \mathrm{~W}$, the model had been simulated under two different conditions - heat source contracting with wall or not contracting with wall. The temperature difference between TV and TC test can be seen in Table 2 .

Table 2. Temperature comparison

\begin{tabular}{|c|r|c|c|c|c|c|c|}
\hline \multirow{2}{*}{ Power(W) } & Heat Flux $\left(\mathrm{W} / \mathrm{m}^{2}\right)$ & \multicolumn{4}{|l|}{ Without Conduction } & \multicolumn{3}{l|}{ With Conduction } \\
\cline { 3 - 8 } & & $\mathrm{TV}\left({ }^{\circ} \mathrm{C}\right)$ & $\mathrm{TC}\left({ }^{\circ} \mathrm{C}\right)$ & Difference $\left({ }^{\circ} \mathrm{C}\right)$ & $\mathrm{TV}\left({ }^{\circ} \mathrm{C}\right)$ & $\mathrm{TC}\left({ }^{\circ} \mathrm{C}\right)$ & Difference $\left({ }^{\circ} \mathrm{C}\right)$ \\
\hline 0.5 & 7.94 & -16.97 & -19.31 & 2.34 & -19.19 & -19.46 & 0.27 \\
\hline 1 & 15.89 & -15.23 & -18.85 & 3.62 & -18.50 & -19.01 & 0.52 \\
\hline 2 & 31.77 & -11.75 & -17.95 & 6.20 & -17.11 & -18.12 & 1.01 \\
\hline 5 & 79.43 & -1.90 & -15.25 & 13.35 & -12.96 & -15.44 & 2.48 \\
\hline 10 & 158.85 & 13.31 & -10.78 & 24.08 & -6.14 & -10.99 & 4.86 \\
\hline
\end{tabular}

The simulation results and the rule number analysis in table above follow same trend. When heat flux of heat source is greater than $40 \mathrm{~W} / \mathrm{m}^{2}$ and without contracting with walls, there may be a significant 
temperature difference between $\mathrm{TV}$ and $\mathrm{TC} \operatorname{test}\left(>10^{\circ} \mathrm{C}\right)$. It may be in consequence short-test for article. The threshold should be much greater than $40 \mathrm{~W} / \mathrm{m}^{2}$ for a unit directly contracting to deck and could be estimated by equ. 9 using heat flux and characteristic length ratio.

\subsection{Test}

The comparative test was carried out in BISEE; specifically, the TC test was done in thermal cycling chamber and TV test was completed in thermal vacuum chamber. test article was a rectangular cuboid which dimensions are $600(\mathrm{~L}) \times 400(\mathrm{~W}) \times 300(\mathrm{H}) \mathrm{mm}$. Inner structure of the article was same as the model in 3.1. The test article and test system are showed in Figure 7. There were four programmable power supplies and film heaters used to simulate the heat source. Also, sixteen thermal couples were set on test article to measure the temperature.

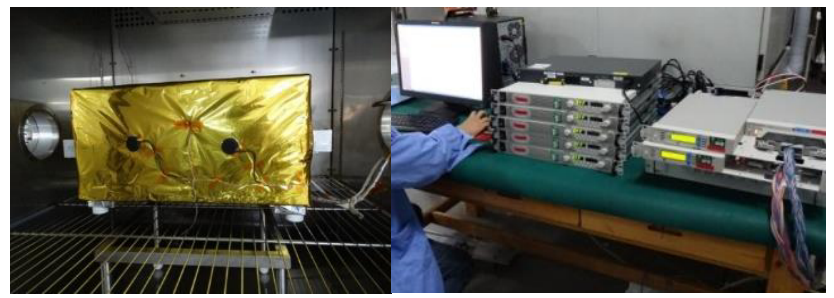

Figure 7. Test article and test system

When the shell temperature was $273 \mathrm{~K}$ and $353 \mathrm{~K}$ separately, the temperature difference between TC and TV test was calculated by equ.9. The curves are showed in Figure 8.

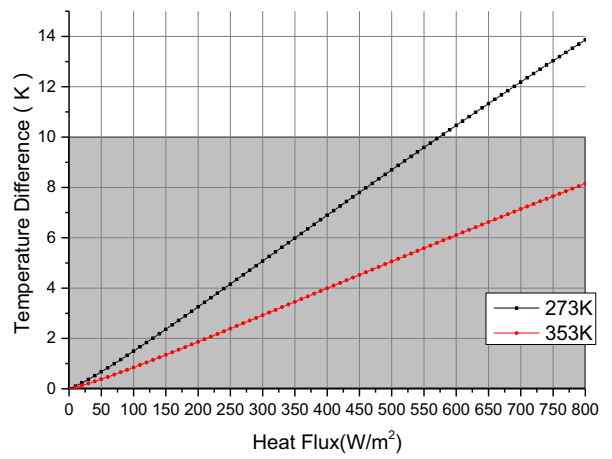

Figure 8. Temperature difference between TC and TV test

To verify the analysis, heat flux of the heat source was set to $750 \mathrm{~W} / \mathrm{m}^{2}$. According to the analysis, temperature difference between TC and TV test will be less than $10^{\circ} \mathrm{C}$ in $353 \mathrm{~K}$ case, and it will be more than $10^{\circ} \mathrm{C}$ in $273 \mathrm{~K}$ case. The test result is showed in Table 3 .

Table 3. Temperature difference in TC and TV test

\begin{tabular}{|l|l|l|l|}
\hline \multirow{2}{*}{ Case } & \multicolumn{3}{|l|}{ Temperature difference between shell and heat source $\left({ }^{\circ} \mathrm{C}\right)$} \\
\cline { 2 - 4 } & TV test & TC test & Delta \\
\hline $273 \mathrm{~K}$ & 43.89 & 20.37 & 23.52 \\
\hline
\end{tabular}




\begin{tabular}{|l|l|l|l|}
\hline $353 \mathrm{~K}$ & 20.89 & 19.34 & 1.55 \\
\hline
\end{tabular}

It can be seen that test result follow same trend with the rule number analysis. The temperature difference between TV and TC in low temperature was larger than in high temperature case. If a heat source thus set on deck directly, the heat flux threshold for alternative thermal cycling test can be calculated by the rule number analysis method.

\section{Conclusion}

In this paper, an internal heat transfer model coupled radiation, convection, conduction has been built by simplified nanosatellite model. Via rule number analysis method, it describes the applicability of using TC instead of TV for nanosatellite whose characteristic length and heat source size are different. Analysis results show it is feasible to use alternative TC test for nanosatellites with inner heat source flux less than $40 \mathrm{~W} / \mathrm{m}^{2}$. For a nanosatellite with internal heat source directly installed on deck, the threshold could be extended to $100 \mathrm{~W} / \mathrm{m}^{2}$, which can be calculated by rule number analysis method. The results of CFD and test method used to verification are consistent with the rule number analysis. The analytical method in this paper could be a positive choice in test method of nanosatellite in the future.

\section{References}

1. M. Cho, H. Masui, T. Hatamura, K.Date, S.Horii, S. Obata, Status of Micro/Nano satellite Environmental Tests Standardization Project: Test Campaign and Standard Draft. (Nanosatellite Symposium, La Seine, 2016)

2. M. Cho, H. Masui, T. Hatamura, K.Date, S.Horii, S. Obata, Overview of Nano-satellite Environmental Tests Standardization Project: Test Campaign and Standard Draft.(26th Annual AIAA/USU Conference on Small Satellites, Logan, UT, 2012)

3. ISO/TC 20 / SC 14 N 1004, Space Systems — Design Qualification And Acceptance Tests Of Small-Scale Satellite And Units Seeking Low-Cost And Fast-Delivery. (2014)

4. O.G. Martynenko, P.P. Khramtsov, Free-Convective Heat Transfer: With Many Photographs of Flows and Heat Exchange.(2005)

5. SMC-S-016A, Test Requirements For Launch, Upper Stage And Space Vehicle. (2014)

6. MIL-STD-1540C, Test Requirements For Launch, Upper Stage And Space Vehicle. (1994)

7. J. Bouwmeester, J. Guo, Survey of worldwide pico- and nanosatellite missions, distributions and subsystem technology, Acta Astronaut, 67, 854-862(2010) 